\title{
Prioritising the implementation of practices to overcome operational barriers in reverse logistics
}

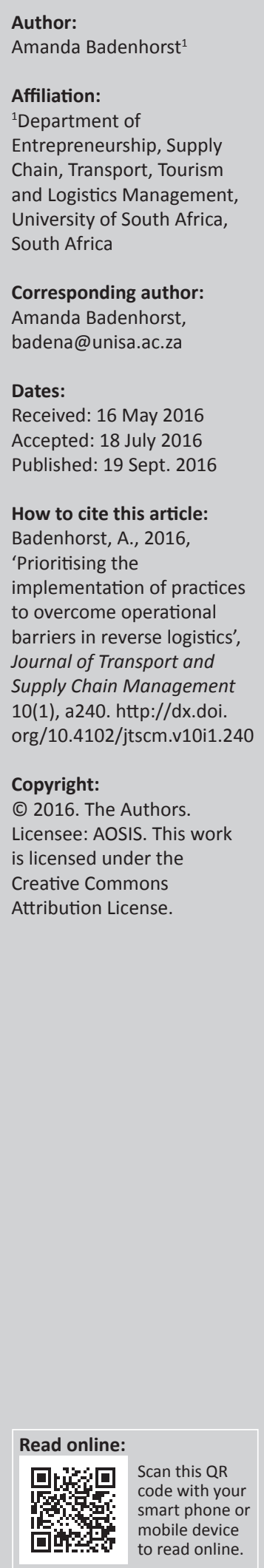

Background: Reverse logistics is a complex process, and many organisations experience operational barriers that prevent them from successfully managing the process. This study overcomes the gap in research regarding the most important practices that organisations can implement to overcome operational barriers in reverse logistics.

Objectives: The study aims to identify operational barriers preventing the efficient performance of the reverse logistics process, matching them to applicable practices by means of a theoretical framework and prioritising the implementation of appropriate practices with the inputs of practitioners.

Method: The study used a survey method, and data were collected by means of a questionnaire based on a theoretical framework that was sent to organisations that offered reverse logistics as a service or specialised in reverse logistics in South Africa. The study used descriptive statistics to conduct a gap-and-opportunity analysis.

Results: Respondents were asked to indicate the importance of the practices and how difficult they would be to implement. Results showed that all the practices are important to at least a moderate extent but some are more difficult to implement.

Conclusion: The framework developed in this article will enable organisations to identify the operational barriers they experience in reverse logistics and the practices they can implement on a priority basis to overcome these barriers.

\section{Introduction}

\section{Background}

Reverse logistics is one of the most important issues in the supply chain (Ganjali, Shirouyehzad \& Shahin 2014:51) and has received growing attention in the past few decades (Rajagopal, Sundram \& Naidu 2015:39). Despite the increasing recognition of the importance of reverse logistics, many organisations are reluctant to meet the challenges involved in handling returns (Srivastava 2013:67). Unfortunately suppliers, manufacturers, wholesalers and retailers are still perceiving reverse logistics as a 'necessary evil' in their everyday operations rather than an opportunity for future performance (Genchev, Richey \& Gabler 2011:242).

Reverse logistics starts where the conventional principles of supply chain management end (Sharma et al. 2011:101). It is a systematic process that manages the flow of products, parts and information from the point of consumption to the point of origin, by extending a product's traditional life cycle (Rajagopal et al. 2015:39).

Reverse logistics has certain characteristics indicating the nature of the activity, namely: (1) it links the physical movement of all recovered materials from the customers to the suppliers (Mishra \& Napier 2014:34); (2) it is induced by various forms of used products and materials (Li et al. 2012:1); (3) it involves the flow of products back upstream through the supply chain (Mishra \& Napier 2014:33); (4) it includes completing the return of materials and acquiring related information (Mishra \& Napier 2014:38); (5) it involves the management of any type of returns from any customer with the aim of lowering costs and increasing profits and (6) it is a complicated process that is difficult to manage (Lhafiane, Elbyed \& Bouchoum 2015:369).

Reverse logistics features greater relative uncertainty in comparison with forward logistics flows (Bai \& Sarkis 2013:306). It is different in terms of quantity, quality and time of return (Jindal \& Sangwan 2015:394; Kannan, Pokharel \& Kumar 2009:28), and it is a much more reactive process (Rajagopal et al. 2015:41). It is seldom that organisations initiate reverse logistics activity as a result Note: This article is partially based on the author's thesis of the degree of Master of Commerce in Logistics at the University of South Africa, South Africa, with supervisor Prof. C. van Zyl, received February 2013, available here: http://hdl.handle.net/10500/10004 
of proactive planning measures. Rather, they do it in response to external downstream partners or customers (Bai \& Sarkis 2013:306). For reverse logistics processes to be successful, organisations usually require specialised infrastructure with unique information systems for tracking, dedicated equipment for the processing returns (Kannan et al. 2009:28), trained manpower, other value-added services and flexibility to deal with operational issues (Prakash \& Barua 2016:64). As a consequence, many organisations have typically pushed aside the issue of returns, preferring to focus only on the forward flow (Shukla 2015:84).

In essence, reverse logistics is a complex and dynamic process and not merely a reversal of the direction of the supply chain. Product returns are becoming inevitable across all industries, and returns can occur at any time during the product life cycle (Shaik \& Abdul-Kader 2014:87). However, it is important to mention that while many challenges or barriers are experienced in reverse logistics, it offers many opportunities that forward logistics does not (Rogers, Melamed \& Lembke 2012:111).

According to Rogers et al. (2012:107), reverse logistics has become an area of concern to professionals, and the tools needed to explore reverse logistics in a systematic manner have not yet been completely identified or described. As a result, many organisations are inefficient in the handling of their reverse logistics processes (Lambert, Riopel \& AbdulKader 2011:562) and have not yet designed and implemented optimal processes for effective reverse logistics management (Mishra \& Napier 2014:46). Therefore, it is important to understand the main forces governing reverse logistics and gain insight into the challenges and opportunities for efficiency and effectiveness (Coyle et al. 2013:634).

\section{Previous studies}

In the literature, there is evidence of studies that focused on the barriers in reverse logistics and others that focused on practices. During a literature study for this article, the researcher found evidence of recent studies on barriers in reverse logistics in developing countries. For instance, Laribi and Dhouib (2015) evaluated the main barriers that hinder Tunisian organisations from successfully implementing reverse logistics. Similarly, Sharma et al. (2011) analysed the different barriers that hinder the successful implementation of reverse logistics in India. Starostka-Patryk et al. (2013) analysed the different barriers in reverse logistics in Poland. Likewise, Abdulrahman, Gunasekaran and Subramanian (2014) conducted a quantitative survey reviewing the critical barriers that prevent manufacturing organisations from implementing reverse logistics in China. Finally, Bouzon Govindan, Rodriguez and Campos (2016) have conducted research focusing on the barriers of reverse logistics in Brazil.

There are not many studies that focus on investigating practices to overcome barriers or finding solutions in reverse logistics. One study, conducted by Mishra and Napier (2014:38), investigated factors that led to the successful implementation of reverse logistics. However, there are a few studies that focus on specific practices or issues to improve reverse logistics processes. For instance, Bai and Sarkis (2013) focused on flexibility as a practice to overcome uncertainty in reverse logistics. Genchev et al. (2011) investigated formalisation as a way of improving reverse logistics flows. Similarly, Kaynak, Koçoğlu and Akgün (2014) focused on centralisation as a practice to manage the reverse logistics process. Olorunniwo and Li (2010) investigated how information technology, information sharing and collaboration in the supply chain can impact an organisation's performance in reverse logistics.

Limited research studies had been conducted on the barriers and practices in reverse logistics in South Africa. However, in one study, Badenhorst (2013a) focused on cost-related problems and solutions in reverse logistics in South Africa. In a similar study, Prakash and Barua (2015) focused on identifying and ranking solutions to overcome barriers in reverse logistics in the electronics industry. They used an analytical hierarchical process to determine weights for the criteria barriers and to prioritise the solutions. However, they did not match practices or solutions to the barriers they have identified.

\section{Problem statement}

As indicated above, several studies focused on the barriers in reverse logistics, but the researchers generally did not investigate or propose solutions to overcome these barriers. For instance, Bouzon et al. (2016:194) indicated that one limitation in their research is that their framework for the barriers in reverse logistics does not indicate any solutions to overcome the barriers. Similarly, Abdulrahman et al. (2014), Laribi and Dhouib (2015), Sharma et al. (2011) and StarostkaPatryk et al. (2013) conducted studies on the barriers in reverse logistics but did not focus on practices to overcome these barriers.

Considering the gaps in research, this study aims to develop a theoretical framework for matching operational barriers and applicable practices and seek inputs from practitioners to prioritise the implementation of applicable practices. This study will (1) use literature to identify the most significant operational barriers in reverse logistics, (2) use the literature to discuss potential practices to overcome these barriers, (3) develop a theoretical framework from the literature to indicate how certain practices can overcome operational barriers in reverse logistics, (4) conduct a survey by means of a questionnaire to find the most important practices and prioritise these practices according to their importance and ease of implementation and (5) conduct a gap-andopportunity analysis based on the survey results to develop a priority list for the implementation of practices.

The article will begin with an introduction to the study containing the background, an overview of previous studies, the problem statement and an outline of the contribution to the field. This will be followed by a literature 
study, which will include an overview of the reverse logistics process, the operational barriers in reverse logistics, the practices to overcome operational barriers in reverse logistics and a theoretical framework showing how certain practices can overcome the operational barriers in reverse logistics. Then, the research design and methodology will be discussed. This will be followed by a presentation of the results of the survey and the gap-and-opportunity analysis. Then there will be a discussion of the results, where the final framework for prioritising practices to overcome operational barriers in reverse logistics will be presented. The article will end with limitations and recommendations as well as a conclusion.

\section{Contribution to the field}

Reverse logistics as a research area is essential (Bajor \& Babić 2014:168) and is a relevant area for both practitioners and academics to explore (Harris \& Martin 2014:11). Considering the little attention given to reverse logistics in organisations and the gaps identified in research, this study and article will contribute to the literature and research on reverse logistics in South Africa.

Reverse logistics is a mandatory component of the supply chains in developed countries (Bouzon et al. 2016:184) but is still in a state of infancy in emerging economies (Abdulrahman et al. 2014:460; Bouzon et al. 2016:184), such as South Africa. Therefore, this research and article will also help to focus the attention of practitioners on the importance of reverse logistics and indicate how operational problems could be solved. Many organisations appear to have no formal plan in place to deal with returns and are inefficient in the handling of their reverse logistics processes (Lambert et al. 2011:562). The framework developed in this study will provide insight into those practices that are important and easy to implement to overcome barriers in operational processes in reverse logistics. According to Prakash and Barua (2015:574), there is a need for solutions to overcome the barriers in reverse logistics. Therefore, it is desirable to adopt reverse logistics practices, and feasible solutions must be projected and ranked so that the barriers in reverse logistics may be overcome on a priority basis (Prakash \& Barua 2015:559). The research in this article makes a contribution in this regard.

\section{Literature study The reverse logistics process}

Reverse logistics has been defined in different ways (Agrawal, Singh \& Murtaza 2015:77). The scope of reverse logistics throughout the 1980s was limited to the movement of material against its primary flow (Bernon, Rossi \& Cullen 2011:486). Some of the more recent definitions in reverse logistics contain various elements. For instance, Kussing and Pienaar (2012:447) have defined reverse logistics as 'that part of returns management that plans, implements and controls the efficient and effective flow of goods and related information from the point of consumption to the point of recovery in order to recapture value or properly dispose of the goods'. Furthermore, Kussing and Pienaar (2012:447) have explained the elements in the definition of reverse logistics as follows: 'Goods' can cover raw materials, inprocess inventory, finished goods, containers and packaging and waste materials.

The flow of 'goods' takes place in an upstream (reverse) direction within a supply chain, and the flow of waste takes place laterally or away from the supply chain. The flow can be between any intermediate point in the supply chain, including manufacturing returns, distribution returns from retailers and wholesalers and consumer returns.

However, Wang, Liu and Wei (2013:45) have stated that the flows also include information flow, cash flow and all parts of business flow.

Reverse logistics involves a number of key processes (Agrawal et al. 2015:77). When receiving a request to return a product, the seller must organise, retrieve and then determine the outcome of the returned product (Harris \& Martin 2014:1). The general processes in reverse logistics are customer return request (Bernon et al. 2011:491), gatekeeping, collection, inspection or sorting and disposition (Agrawal et al. 2015:77; Lambert et al. 2011:561).

Figure 1 provides a graphic presentation of the key processes in reverse logistics.

The first process involves the notification of a product return (Lambert et al. 2011:561), which is known as a customer return request (Bernon et al. 2011:491). The second process in the reverse logistics process is gatekeeping, which is the authorisation of the product return as well as important information regarding the particular return (Bajor \& Babić 2014:162). The next process in reverse logistics involves collection, where returned products are delivered to the facilities for inspection, sorting and disposition (Agrawal et al. 2015:78). Inspection and sorting take place when the overall appearance and state of the returned products are evaluated more intensively than during gatekeeping (Agrawal et al. 2015:78). Inspection will determine the condition of the returned product (Rubio \& Jimenez-Parra 2014:3), and sorting refers to the decisions about what to do with products, for example, segregating them into categories, such as defective or nondefective (Shaik \& Abdul-Kader 2014:97). Disposition is the final process in reverse logistics (Agrawal et al. 2015:78) and refers to the exit route that the returned product will take (Bernon et al. 2011:492). With product returns, a wide range of disposition options exist, all with different revenue streams (recovery options) (Rogers et al. 2012:108).

The disposition options can be categorised as reuse, product upgrade, material recovery and waste management (Hazen, Hall \& Hanna 2012:248). Figure 2 provides an illustration of the disposition process and options. 


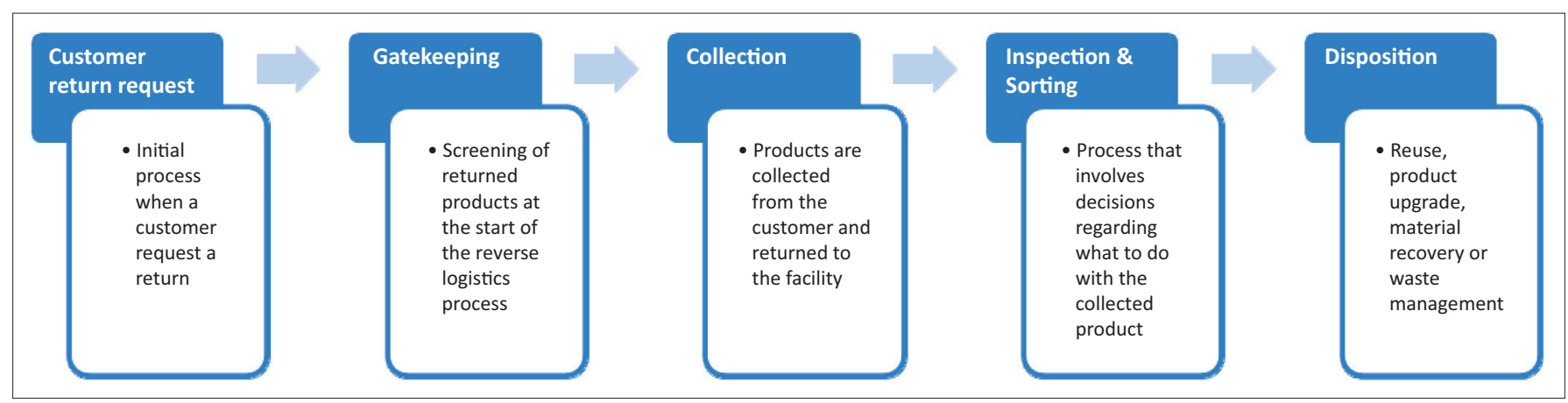

FIGURE 1: Reverse logistics process activities.

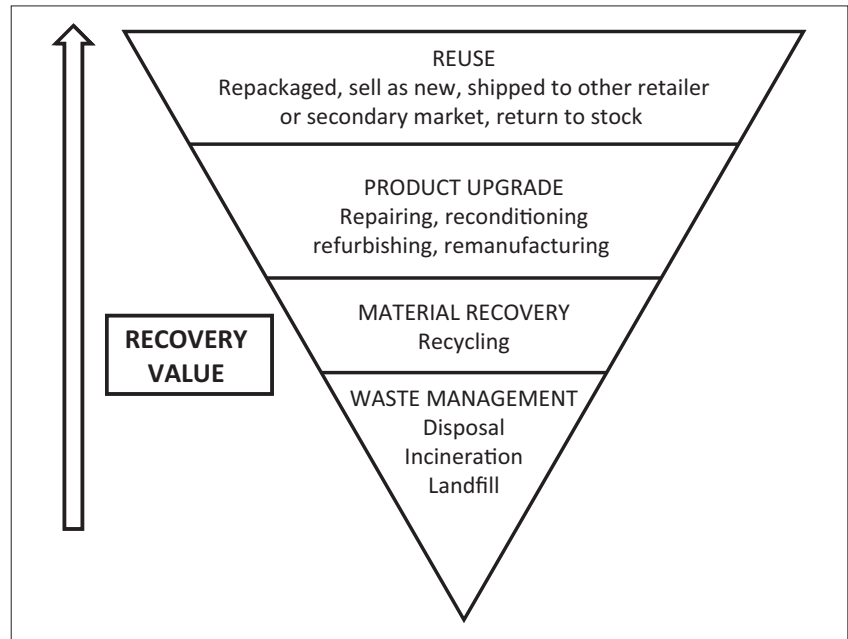

FIGURE 2: Disposition options and recovery value.

As seen in Figure 2, reuse entails reusing or reselling the returned product in its current condition. In reuse, products are returned directly to inventory or repackaged and returned to inventory (Stock \& Mulki 2009:42). Product upgrade involves repairing, reconditioning, refurbishing or remanufacturing and becomes an option if reuse is no longer available. Product upgrade implies improving the product from its end-of-life or end-of-use condition to a condition that is acceptable for future use or sale (Hazen et al. 2012:249). Material recovery involves recovering any portion of a returned product that may contain value (Hazen et al. 2012:249). It includes recycling, which involves recovering parts or extracting recyclable materials for reuse (Chan, Chan \& Jain 2012:1324; Hazen et al. 2012:249). Finally, waste management is where an organisation decides that there is no longer value to reuse, upgrade or recover in the materials and the product becomes waste (Hazen et al. 2012:249). The option in waste management is disposal, which involves landfilling or incinerating parts or products provided that other disposition options are no longer available and that the materials are not worthy of recovery and sales at aftermarket (Khor \& Udin 2012:7).

\section{Operational barriers in reverse logistics}

Reversing the flow of products is a challenge to most organisations in terms of the physical activities (Aitken \& Harrison 2013:746). Operational barriers include problems related to the effective management of reverse logistics processes. The operational barriers that were identified in literature include inconsistent product quality, limitations to forecasting and visibility, inadequate information and technological systems and development barriers. Each of these barriers will be discussed in the rest of this section.

\section{Inconsistent product quality}

In reverse logistics, the quality of products is not uniform as in the case of forward logistics (Sharma et al. 2011:102). Reverse logistics also includes the quality of end-of-use or end-of-life returns (Kaynak et al. 2014:440). As the quality of returned products is uncertain, organisations find it hard to estimate product value, which leads to the problem of control and managing financial aspects of reverse logistics (Lee \& Lam 2012:596).

\section{Limitations to forecasting and visibility}

Accurate return forecasts are hardly available, which is a direct barrier to both strategic and operational planning (Janse, Schuur \& De Brito 2010:501; Sharma et al. 2011:103). Limited visibility of returns also acts as a barrier in many organisations (Srivastava 2013:65). Reverse logistics is a reactive process because of less visibility, which makes planning and decision making complex (Rajagopal et al. 2015:41). Therefore, there is a lack of knowledge about return volume as well as an unpredictable demand on recovered materials (Starostka-Patryk et al. 2013:507).

\section{Inadequate information and technology systems}

Most logistical information systems do not make provision for the reverse flow of materials (Janse et al. 2010:501; Kaynak et al. 2014:440; Sharma et al. 2011:103; Starostka-Patryk et al. 2013:506). One of the most significant problems that organisations face in executing the reverse logistics process is the scarcity of good information systems (Myerson 2015:168). Strong information support is a requirement for effective decision making in reverse logistics (Mai, Chen \& Anselmi 2012:49). Most organisations have mature information and technology systems to support forward logistics, but reverse logistics still needs further improvement (Lee \& Lam 2012:596). Therefore, reverse logistics often involves manual recording of data, with the possibility of human errors or inconsistencies caused by the duplication of tasks, a lack of technological equipment and a lack of information technology tools (Awasthi \& Chauhan 2012:114). If there is a lack of 
efficient and accurate information support to authorise, track and handle returns, it could lead to costly mistakes and inefficiencies (Mai et al. 2012:49). Consequently, the lack of the development of appropriate technology hampers the efficiency of reverse logistics processes (Srivastava 2013:66). This is because information technology, software and hardware are essential for end-to-end control and transparency in the reverse logistics process (Sharma et al. 2011:103).

\section{Developmental barriers}

Organisations face operational weaknesses and system deficiencies that are partly caused by inadequate infrastructure (Bai \& Sarkis 2013:307; Srivastava 2013:65). Many organisations do not have the expertise, manpower or infrastructure for processing returns and expanding to start up a new operating system of returns (Shukla 2015:86). The lack of development greatly increases uncertainty in the effective management of reverse logistics (Bai \& Sarkis 2013:307). Essentially, a good reverse logistics infrastructure will enable an organisation with the capabilities to handle returns quickly and efficiently (Abdulrahman et al. 2014:463).

\section{Possible practices to overcome operational barriers in reverse logistics}

From the literature, various practices were identified for overcoming operational barriers in reverse logistics. This includes the use of the Internet or the World Wide Web, returns software, state-of-the-art technology, reverse logistics information and management systems, standardising reverse logistics processes, establishing a gatekeeping function, centralised return centres (CRCs), clear return policies, return avoidance strategies, outsourcing and collaboration and information sharing with supply chain partners. These practices will be discussed in the rest of this section.

\section{Utilise the Internet and adopt a web-based approach}

To overcome issues such as a lack of control and information about the return flow, organisations can invest in wireless technologies (Li et al. 2015:26). Organisations can also address visibility problems by using the Internet or adopting a webbased approach (Hammrich 2007:28; Patrican \& Kirk 2009:14). With a web-based approach, organisations can capture the reasons for product returns, determine the quality of a product and evaluate customers' return habits (Hammrich 2007:28) (Badenhorst 2013b). In addition, to overcome human error and inconsistency with manual data recording, organisations can utilise technology solutions such as the Internet, wireless mobile telecommunication technologies and product identification technologies. These technologies can be used for item tracing and real-time data management to ensure improved reverse logistics operations (Awasthi \& Chauhan 2012:114).

\section{Utilise return software, state-of-the-art technology and reverse logistics information management systems and technology}

The three elements under this heading are integrated in this discussion because of the fact that they have many functions and advantages of implementation overlapping. However, they have been separately indicated in the research instrument. Prakash and Barua (2015:13) have found that investing in state-of-the-art technology for reverse logistics is one of the top solutions for overcoming operational barriers in reverse logistics. The correct software and technological and information management systems are essential for successfully managing reverse logistics operations (Lambert et al. 2011:563). Returns software, state-of-the-art technology and reverse logistics information management systems have track-and-trace functions that improve the visibility of returned goods and thus improve the management of the reverse flow of goods (Greve \& Davis 2012:136; Mai et al. 2012:49; Rohan, Varum \& Hulgur 2012:889; Rupnow 2011:35; Saikiah, McRoberts \& Thakur 2016:18;). In addition, it centrally collects and makes available high-quality information on the return flows (Rupnow 2011:36; Wang et al. 2013:48). The returns software and information management system indicates the reason for the return flows, alternative disposition options (Lambert et al. 2011:563; Rohan et al. 2012:889; Saikiah et al. 2016:18), as well as decision rules and tools (Rupnow 2011:36). Return software and a reverse logistics information management systems provide the ability to communicate information and integrate with supply chain partners so as to present a unified view of the returned goods (Lambert et al. 2011:563; Rohan et al. 2012:889; Rupnow 2011:36; Saikiah et al. 2016:18).

\section{Standardisation of reverse logistics processes}

Reverse logistics, by its very nature, would seem to be an ideal candidate for the development of standardised methods (Tiwari 2013:241). With product returns on the rise, many organisations strive to standardise the reverse logistics process (Shukla 2015:86) so that they can create their own procedures and standards to improve returns handling (Huang \& Yang 2014:626). Standardisation of processes in reverse logistics has certain benefits. Firstly, standardisation will help to increase visibility of returns (Genchev et al. 2011:258). Secondly, it can improve operating flexibility and achieve operating efficiency. Efficiency is improved because formal rules and procedures eliminate the need to treat every event as a new decision (Tiwari 2013:242). Finally, standardised procedures can help to reduce conflict and confusion in reverse logistics operations (Huang \& Yang 2014:635; Lee \& Lam 2012:596). Knowing exactly what is involved in managing the returns flow is necessary for reducing ambiguity and the number of uncertainties in reverse logistics (Genchev et al. 2011:246).

\section{Establish a gatekeeping function}

Gatekeeping is the screening of defective or unwarranted returned products at the start of the reverse logistics process (Myerson 2015:167). Therefore, in gatekeeping the organisation uses filters as a preliminary measure to determine which products are allowed to enter the reverse logistics system and which are to be rejected (Lambert et al. 2011:563). Successful gatekeeping allows organisations to control and reduce the rate of returns (Agrawal \& Choudhary 2014:19; Shukla 2015:86). In addition, authorising returns 
makes it much easier for organisations to identify fraudulent returns (Bernon et al. 2011:492).

\section{Establish centralised return centres}

CRCs have become a widespread solution for providing centralised sorting and return disposition services (Saikiah et al. 2016:9). Although products are shipped in both forward and reverse logistics, the conditions are different. Traditional forward centres are designed to ship goods out and handle goods that have already been organised in pallets and boxes in uniform sizes. By contrast, return centres receive a variety of products that are returned in any type of box or package (Dutton 2010:1) (Badenhorst 2013b). Essentially, CRCs specialise in returns and can offer benefits such as consistency in disposition decisions, faster disposition times and easier identification of trends in returns to identify quality problems (Myerson 2015:169; Saikiah et al. 2016:9).

\section{Establish clear policies for reverse logistics}

Bernon et al. (2011:491) have found that if reverse logistics operations are to be managed effectively, return policies need to be managed at a more strategic level. Return policies should be properly designed, defined and communicated to all stakeholders (Srivastava 2013:68). For returns to be managed, understandable and enforceable return policies must be established (Patrican \& Kirk 2009:14). By creating clear return policies, organisations can improve control over returns, minimise fraudulent returns (Genchev et al. 2011:251) and reduce the number of returns (Srivastava 2013:68).

\section{Implement return avoidance strategies or zero-return policies}

Organisations are starting to realise that the easiest way to deal with returned goods is to reduce their volume (Rogers et al. 2012:114). Return avoidance is part of a clear reverse logistics strategy and should be a priority (Janse et al. 2010:502). Organisations need to identify the reasons behind product returns in order to implement effective return avoidance strategies (Rohan et al. 2012:889). Measuring and rewarding return avoidance initiatives can increase the predictability and manageability of product returns (Janse et al. 2010:508). Another important issue in many industries is that of zero-return policies, which means that the customer does not physically return the item (Rogers, Lembke \& Benardino 2013:44). Zero-return policies normally take place where the manufacturer does not accept returns from its customer, the retailer (Myerson 2015:169). Instead, the customer takes a credit allowance from the supplier (Rogers et al. 2013:44). These policies give the retailer an allowable return rate and propose guidelines as to the proper disposition of an item (Myerson 2015:169).

\section{Outsourcing reverse logistics to third parties}

Many organisations outsource their reverse logistics operations to a third-party logistics (3PL) provider (Lambert et al. 2011:563). A 3PL partner can play a crucial role in the adoption and effective implementation of reverse logistics operations (Prakash \& Barua 2016:67) because it has a solid understanding of the issues to be addressed in reverse logistics and in-depth knowledge about industry practices across the supply chain (Rogers 2010:38). Therefore, outsourcing to 3PL providers can be a means of overcoming numerous operational barriers. For instance, 3PL providers employ state-of-the-art technologies and can customise their services to address their partner's needs (Prakash \& Barua 2016:67; Rogers 2010:38), they can achieve real-time tracking (Wang et al. 2013:49), analyse reasons for product returns, improve product quality or use the relative information to predict future trends (Wang \& Zhang 2009:2062), which can result in improved inventory management, increased visibility and greater control over reverse logistics operations (Robinson 2015:3).

\section{Collaborate and share information with supply chain partners}

Managing successful coordination of reverse logistics in the supply chain requires collaboration (Prakash \& Barua 2015:4). The ability to collaborate with various players in the reverse chain is as important as in the forward chain. Actually, what makes a forward supply chain successful is the collaboration, visibility and trust of the various entities in the chain. This is also true for the reverse chain (Olorunniwo \& Li 2010:455). The success of reverse logistics operations requires organisations to improve supply chain relationships through regular meetings and exchanges of information (Aitken \& Harrison 2013:759). Such information exchange enhances operational efficiency in reverse logistics and provides greater visibility (Olorunniwo \& Li 2010:456; Partida 2011:63). In addition, technology-enabled engagements should assist in addressing the growing problem of product returns (Morgan, Glenn \& Chad 2016:295), which in turn will enable organisations to avoid unnecessary product returns (Partida 2011:63). Therefore, best-in-class logistics performers will possess strong collaborative relationships and seek competencies in both information technology and reverse logistics (Morgan et al. 2016:312).

Table 1 provides a theoretical framework based on literature findings, indicating how each potential practice can overcome a specific operational barrier in reverse logistics.

In Table 1, practices that were identified in literature have been matched with operational barriers in reverse logistics identified in literature. To this point, the first three of the study aims have been attained, namely, to: (1) identify the most significant operational barriers in reverse logistics by means of the literature, (2) identify potential practices for overcoming these operational barriers by means of a literature study and (3) develop a theoretical framework from the literature that matches the barriers with practices that may offer solutions for overcoming the operational barriers in reverse logistics.

Some of the practices discussed and tabled are easier to implement than others in terms of the resources needed and know-hows. The researcher felt it necessary to consult a number of practitioners to obtain their inputs regarding the 
TABLE 1: Theoretical framework of practices to overcome operational barriers in reverse logistics. Potential practice

\begin{tabular}{|c|c|c|c|c|}
\hline \multirow[t]{2}{*}{ 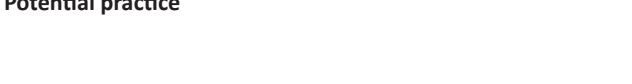 } & \\
\hline & $\begin{array}{l}\text { Inconsistent product } \\
\text { quality }\end{array}$ & $\begin{array}{l}\text { Limitations forecasting } \\
\text { and visibility }\end{array}$ & $\begin{array}{l}\text { Inadequate information } \\
\text { technology systems }\end{array}$ & $\begin{array}{l}\text { Developmental } \\
\text { barriers }\end{array}$ \\
\hline Utilise the Internet or adopt a web-based approach & $\mathrm{x}$ & $\mathrm{x}$ & $\mathrm{x}$ & - \\
\hline $\begin{array}{l}\text { Utilise return software, state-of-the-art technology and reverse } \\
\text { logistics information management systems }\end{array}$ & - & $x$ & $x$ & - \\
\hline Standardise reverse logistics process & - & $\mathrm{x}$ & - & - \\
\hline Establish a gatekeeping function & $\mathrm{x}$ & $x$ & - & - \\
\hline Establish CRCs & $\mathrm{x}$ & $x$ & - & - \\
\hline Implement return avoidance strategies or zero-return policies & $x$ & $x$ & $x$ & $x$ \\
\hline Outsource to third parties & $\mathrm{x}$ & $\mathrm{x}$ & $\mathrm{x}$ & $\mathrm{x}$ \\
\hline Share information and collaborate with partners & - & $\mathrm{x}$ & $\mathrm{x}$ & - \\
\hline
\end{tabular}

applicability and ease of adoption of the suggested practices. This was done through a survey, which will be discussed below.

\section{Research method and design}

This study was based on quantitative research, and the specific method was a survey, which is usually associated with a deductive approach, where data are used to test theory (Saunders, Lewis \& Thornhill 2012:176). The research was exploratory and descriptive in nature. The materials used in this study included secondary and primary sources of data. In phase 1, the literature study, a theoretical framework was developed and presented earlier in the article. The type of literature sources consulted included journal articles, conference papers, trade or industry magazine articles and books.

In phase 2, the theoretical framework was used as a basis for developing the research instrument - a questionnaire - to conduct the survey. The questionnaire consisted of two parts. Part one provided general information about the study, and Part two included three sections, namely, general information about the responding organisation, barriers in reverse logistics and applicable practices in reverse logistics. A Likert-type response format was used for some of the items. The respondents were asked to rate the importance and applicability of certain practices used in overcoming barriers in reverse logistics from 1 (lesser extent) to 5 (greater extent). Part two also contained an additional response format so that the degree of difficulty in implementing the practices could be determined. The responses could be (1) very easy, (2) somewhat easy, (3) moderately difficult, (4) quite difficult and (5) extremely difficult. The focus of this article is on the importance and degree of difficulty in implementing the practices for overcoming operational barriers in reverse logistics.

A purposive nonprobability sampling technique was used. Judgemental sampling is a type of purposive sampling, which allows researchers to select cases that will best enable them to achieve their research objectives (Saunders et al. 2012:287). In this study, it was necessary to select respondents who met certain criteria. Respondents (managers at organisations) who were involved in or offered reverse logistics as a service or specialised in reverse logistics (3PLs) in South Africa were identified with an initial search through
Google. It became apparent that a limited number of organisations in South Africa specialise in reverse logistics. Therefore, the sample included 19 organisations. For purposes of an increased sample size, the questionnaire was also sent to the members of the Chartered Institute of Logistics and Transport South Africa. Most of their members indicated that they are not involved in reverse logistics. However, two organisations indicated that they do practise reverse logistics and were willing to participate (Badenhorst 2013b). The final sample included 21 organisations.

The primary data collection process started with obtaining the contact information of the owners or CEOs of the organisation or managers responsible for reverse logistics in the chosen organisations. The contact information was obtained from the organisations' websites. Because of the geographical distances between the organisations, it was decided that these organisations should be contacted by email. Thirteen organisations responded to the email, and ten were willing to complete the questionnaire. Ten respondents were deemed to be sufficient for the nature of this study (obtaining practitioners' input to applicability and ease of adoption of the suggested practices in the framework). Therefore, a decision was made to go ahead with the capturing and analysis of the data, despite the fact that no inferential statistics would be possible with such a small response.

The data in the questionnaire were captured on an Excel spreadsheet and analysed by means of SPSS v17 (Statistical Package for the Social Sciences). This study used descriptive statistics, and the results were used to conduct a gap-andopportunity analysis. This was done by means of radar graphs (gap analysis) and portfolio matrixes (opportunity analysis). Details of the gap-and-opportunity analysis will be given in the next section.

\section{Results}

In the questionnaire the respondents were asked to indicate the importance of the practices as well as how difficult it would be to implement each practice. The mean values of the results (see Table 2) were used to conduct the gap-and-opportunity analysis. This was done to determine if the practices that were identified in the literature are relevant in South Africa, and if these practices are difficult to implement. In terms of the 
TABLE 2: Mean values of the importance and difficulty to implement practices to overcome operational barriers in reverse logistics.

\begin{tabular}{|c|c|c|c|}
\hline Number & Practice & $\begin{array}{l}\text { Mean values: } \\
\text { Importance }\end{array}$ & $\begin{array}{c}\text { Mean values: } \\
\text { Difficulty to implement }\end{array}$ \\
\hline 1 & Utilise the Internet or adopt a web-based approach & 4.00 & 3.10 \\
\hline 2 & Utilise special return software & 3.11 & 3.44 \\
\hline 4 & Utilise a reverse logistics information management system & 4.00 & 3.10 \\
\hline 5 & Standardise reverse logistics processes & 4.30 & 2.10 \\
\hline 6 & Establish a gatekeeper at the start of the reverse logistics process & 4.10 & 2.00 \\
\hline 8 & Separate reverse logistics facilities from forward facilities by establishing central return centres & 3.60 & 3.70 \\
\hline 9 & Establish clear policies for reverse logistics & 4.50 & 2.40 \\
\hline 10 & Implement return avoidance strategies or zero-return policies & 3.50 & 3.13 \\
\hline 11 & Outsourcing reverse logistics to third-party logistics providers & 3.56 & 3.22 \\
\hline 12 & Share information and collaborate with supply chain partners & 4.20 & 2.70 \\
\hline
\end{tabular}

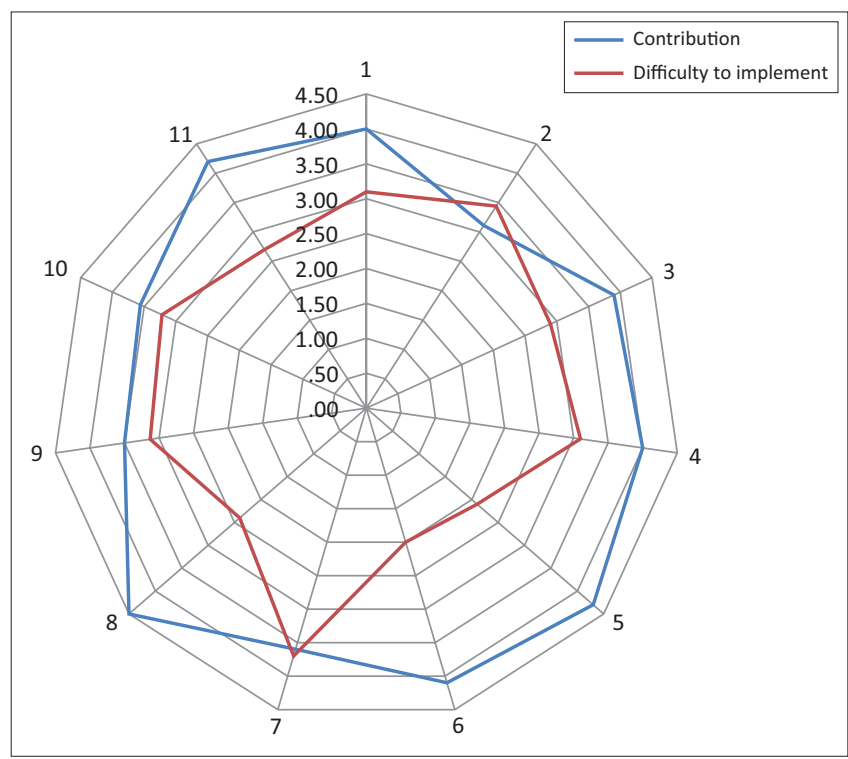

FIGURE 3: Contribution and/or difficulty of implementing practices to overcome operational barriers in reverse logistics.

importance of each practice, a mean value of more than 3 indicates that the practice is important from at least a moderate to a greater extent. In terms of the difficulty to implement the practice, a mean value of more than 3 indicates that the practice may be too cost-intensive or difficult to implement.

\section{Gap analysis}

The radar graph in Figure 3 shows the mean level of (1) the extent of the contribution of each practice and (2) the difficulty of implementing each practice.

From the radar graph, the following most significant observations can be made about the practices (Badenhorst 2013b):

- The practice 'establish clear policies for reverse logistics' (numbered 9) has the highest mean in terms of its contribution (4.50) and the difficulty of implementing it is fairly low, with a mean value of 2.10. Therefore, this practice is important and not too difficult to implement.

- The practice 'standardise the reverse logistics process' (numbered 5) has a high mean level (4.30) in terms of its contribution and a low mean level (2.10) in terms of the difficulty of implementing it. Therefore, this practice is important and does not require too many resources to implement.

- The practice 'share information and collaborate with partners' (numbered 12) has a relatively high mean value (4.20) in terms of its contribution, and the difficulty of implementing it is relatively low, with a mean value of 2.70. Therefore, this practice is important and not too difficult to implement.

- Similarly, the practice 'establish a gatekeeper at the start of the reverse logistics process' (numbered 6) has a fairly high mean level (4.10) in terms of its contribution, and the lowest mean level (2.00) in terms of the difficulty of implementing it. Therefore, this practice is important and is relatively easy to implement.

The four practices identified will contribute a great deal towards the ability to overcome operational barriers in reverse logistics without requiring many resources. Therefore, they are regarded as not too difficult to implement. Consequently, it will make sense for organisations wishing to implement these practices to overcome some of the operational barriers in reverse logistics first. It is important to note that the practice 'utilise special return software' (numbered 2) has a relatively lower mean level (3.11) in terms of its contribution, but the difficulty of implementing this practice has a higher mean level (3.44). Therefore, this practice might be costly to implement and should be carefully considered in terms of value delivered to the organisation.

\section{Opportunity analysis}

An opportunity analysis was conducted for the purpose of determining the extent of the contribution of the practices in relation to the difficulty of implementing them. These practices are discussed by means of a portfolio matrix (see Figure 4).

The portfolio matrix has the following four quadrants (Badenhorst 2013b):

- White elephant - indicates practices with a low level of contribution (low mean values - less than 3) that are difficult to implement (high mean values - higher than 3). 


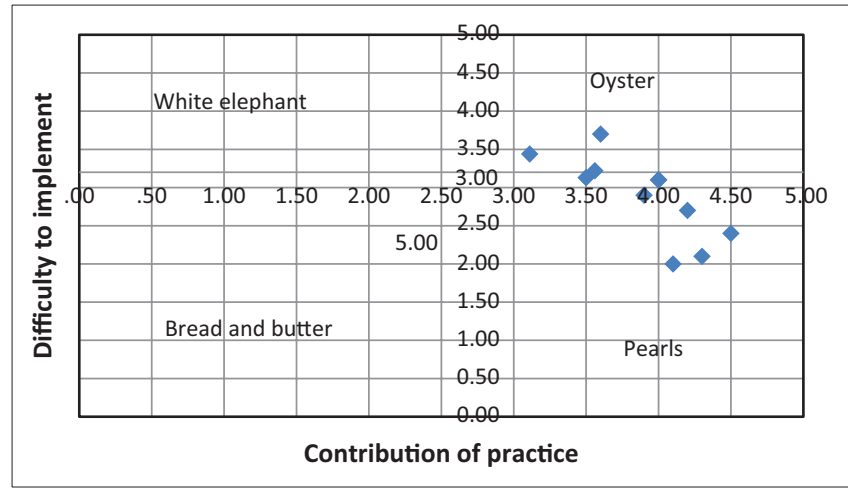

FIGURE 4: Contribution versus difficulty to implement practices to overcome operational barriers in reverse logistics.

- Bread and butter - indicates practices that have a low level of contribution, but are easy to implement (low mean values - less than 3 ).

- Oyster - indicates practices that are important, but are difficult to implement (high mean values - higher than 3).

- Pearl - indicates those practices that are important (high mean values - higher than 3) and are relatively easy to implement (low mean values - less than 3).

The portfolio matrix indicates that all the practices that were identified in literature are indeed perceived to contribute, to at least a moderate extent, to the effective management of reverse logistics (all have mean values above 3.00). Therefore, none of the practices are in the white elephant or bread and butter quadrants, indicating that they are all important to some extent. Additionally, practices in the pearl quadrant (sixth of the 12) are considered to potentially add value and are not too difficult to implement (Badenhorst 2013b). Therefore, these practices should be an organisation's first priority. The remaining six practices that are in the oyster quadrant do add value, but might be difficult or costly to implement. Therefore, these practices should be an organisation's second priority.

\section{Discussion}

In this section, the outline of the results of the final framework for prioritising practices to overcome operational barriers is given together with practical implications.

\section{Outline of results}

Based on the results of the gap-and-opportunity analysis, two frameworks were created. The first framework (Table 3) indicates all the practices that have relatively high contribution values and are also not too difficult to implement. Therefore, these practices should be an organisation's first priority.

Table 4 indicates those practices that appeared in the oyster quadrant of the opportunity analysis, which shows that they are not only relatively important but also difficult or costly to implement. Therefore, these practices should be an organisation's second priority.

\section{Practical implications}

Based on the theoretical framework (see Table 1) that was developed, it is interesting to find that the practices of outsourcing and implementation of return avoidance strategies were considered important because they are the practices that can overcome all the operational barriers in reverse logistics. However, based on the results of this study, these two practices should be a second priority.

Some important practical implications are the following:

- To overcome product quality issues in reverse logistics, organisations should first consider establishing a gatekeeper at the start of the reverse logistics process, implementing a robust gatekeeping function and establishing clear return policies.

- To address issues with limited forecasting and visibility in reverse logistics, organisations can implement a variety of first-priority practices, such as standardising the reverse logistics process, investing in state-of-the-art technology, establishing a gatekeeper or implementing a robust gatekeeping function, establishing clear return policies and sharing information with supply chain partners.

- To overcome the barrier of inadequate information technology systems, organisations can invest in state-ofthe-art technology and collaborate and share information with supply partners. However, if organisations do want to implement special return software, they will have to carefully consider the cost-benefit trade-off.

TABLE 3: Reverse logistics practices in the Pearl quadrant - first priority.

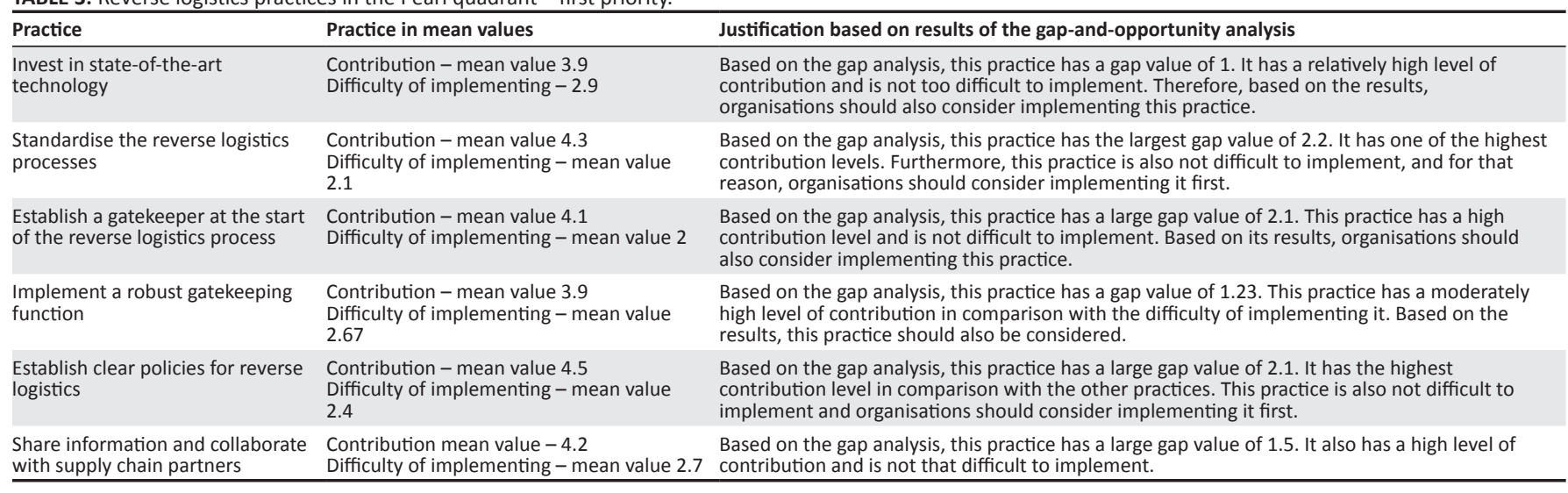


TABLE 4: Reverse logistics practices in the Oyster quadrant - second priority.

\begin{tabular}{|c|c|}
\hline Practice & Practice in mean values \\
\hline $\begin{array}{l}\text { Utilise the Internet or adopt a } \\
\text { web-based approach }\end{array}$ & $\begin{array}{l}\text { Contribution - mean value } 4 \\
\text { Difficulty of implementing - } \\
\text { mean value } 3.10\end{array}$ \\
\hline Utilise special return software & $\begin{array}{l}\text { Contribution - mean value } 3.11 \\
\text { Difficulty of implementing - } \\
\text { mean value } 3.44\end{array}$ \\
\hline $\begin{array}{l}\text { Utilise a reverse logistics } \\
\text { information management system }\end{array}$ & $\begin{array}{l}\text { Contribution - mean value } 4 \\
\text { Difficulty of implementing - } \\
\text { mean value } 3.10\end{array}$ \\
\hline $\begin{array}{l}\text { Separate reverse logistics facilities } \\
\text { from forward facilities by } \\
\text { establishing central returns centres }\end{array}$ & $\begin{array}{l}\text { Contribution - mean value } 3.6 \\
\text { Difficulty of implementing - } \\
\text { mean value } 3.7\end{array}$ \\
\hline $\begin{array}{l}\text { Implement return avoidance } \\
\text { strategies or zero-return policies }\end{array}$ & $\begin{array}{l}\text { Contribution - mean value } 3.5 \\
\text { Difficulty of implementing - } \\
\text { mean value } 3.15\end{array}$ \\
\hline $\begin{array}{l}\text { Outsource reverse logistics to } \\
\text { third-party logistics providers }\end{array}$ & $\begin{array}{l}\text { Contribution - mean value } 3.56 \\
\text { Difficulty of implementing - } \\
\text { mean value } 3.22\end{array}$ \\
\hline
\end{tabular}

Justification based on results of the gap-and-opportunity analysis

Based on the results of the gap analysis, this practice has a gap value of 0.9. This practice has a high level of contribution in comparison with the difficulty implementing it. However, based on the results, it might be costly to implement.

Based on the gap analysis, this practice has a negative gap value of -0.44 . This practice also has the lowest level of contribution in comparison with all the other practices. Therefore the difficulty of implementing it exceeds its contribution. This practice should be an organisation's last priority.

Based on the results of the gap analysis, this practice has a gap value of 0.9 . It has a high level of contribution in comparison with the difficulty implementing it. However, based on the results, it may be difficult to implement.

Based on the results of the gap analysis, this practice also has a negative gap value of -0.1 . This practice has a low level of contribution and it may also be cost-intensive to implement, and for this reason organisations should carefully consider the cost-benefit trade-off.

Based on the gap analysis, this practice has a gap value of 0.42 . It has a moderately high contribution level, but may be too cost-intensive or difficult to implement. Therefore, this practice should be a second priority.

Based on the results of the gap analysis, this practice has a gap value of 0.34 . It also has a fairly high level of contribution, but may be too cost-intensive to implement. Therefore, organisations should carefully consider the cost-benefit analysis.
- With regard to developmental barriers, none of the firstpriority practices identified in this study can overcome them. However, it is important that if organisations find that they have infrastructural problems with regard to reverse logistics, they should consider outsourcing their reverse logistics function.

Essentially, organisations should determine which of these operational barriers are the most problematic. Based on this, organisations can consider implementing the practices proposed in this study.

\section{Limitations and future research opportunities}

One limitation of this study is the small sample size. This is partly because of the fact that there are a limited number of organisations in South Africa that specialise in reverse logistics. In addition, not all the organisations included in the sample were willing to participate. For future purposes, it might be valuable to conduct a qualitative study using interviews to explore the barriers and practices in reverse logistics in South Africa. This will contribute to an understanding of the nuances and contribute to the creation of literature of reverse logistics in South African circumstances.

Finally, the framework that was developed is not industry specific. There may be value in applying the framework to a specific industry or sector to determine if the practices could be more significant or useful in different industries in South Africa.

\section{Conclusion}

A number of research studies have focused on the barriers in reverse logistics, but only a few have focused on practices to overcome these barriers. This study aimed at contributing in this regard. The focus of the article was to identify and prioritise practices to overcome operational barriers in reverse logistics. Based on the literature, the operational barriers in reverse logistics included problems with product quality, limited forecasting and visibility, inadequate information and technology systems and developmental barriers. The practices that were identified for overcoming these barriers included using the Internet or adopting a webbased approach, using return software, state-of-the-art technology and reverse logistics information management systems and technology, standardising the reverse logistics process, establishing a gatekeeping function, establishing CRCs, establishing clear policies for reverse logistics, implementing return avoidance strategies or zero-return policies, outsourcing reverse logistics to third parties and collaborating and sharing information with supply chain partners. Based on the literature, a theoretical framework was developed for matching barriers with possible solutions.

It is not practical to implement all the practices at once. Therefore, it is desirable to prioritise the practices for gradual implementation (Prakash \& Barua 2015:559). In the interests of prioritisation of these practices identified from the literature, a survey was conducted to determine if they are important for organisations in South Africa and if they are considered difficult to implement. The results showed that all the practices are important to at least a moderate extent, but some are more difficult to implement than others. For example, outsourcing and return avoidance were considered a second priority because they might be difficult to implement; therefore, organisations should carefully consider the cost-benefit tradeoff before implementing these two practices. The practices that should be implemented first include state-of-the-art technology, standardising the reverse logistics process, establishing a gatekeeping function, establishing clear policies for reverse logistics and sharing information with supply chain partners.

\section{Acknowledgements Competing interests}

The author declares that she has no financial or personal relationships which may have inappropriately influenced her in writing this article.

\section{References}

Abdulrahman, M.D., Gunasekaran, A. \& Subramanian, N., 2014, 'Critical barriers in implementing reverse logistics in the Chinese manufacturing sectors', International Journal of Production Economics 147, 460-471. http://dx.doi.org/10.1016/ j.ijpe.2012.08.003 
Agrawal, A. \& Choudhary, V., 2014, 'Reverse logistics: Performance measures and their effect in product lifecycle', International Journal of Core Engineering and Management 1(2), 14-22.

Agrawal, S., Singh, R.K. \& Murtaza, Q., 2015, 'A literature review and perspectives in reverse logistics', Resources, Conservation \& Recycling 97, 76-92. http://dx.doi. org/10.1016/j.resconrec.2015.02.009

Aitken, J. \& Harrison, A., 2013, 'Supply governance structures for reverse logistics systems', International Journal of Operations and Production Management 33(6), 745-764. http://dx.doi.org/10.1108/IJOPM-10-2011-0362

Awasthi, A. \& Chauhan, S.S., 2012, 'A RFID integrated quality management system for reverse logistics networks', in Y. Nikolaidis (ed.), A broad look on quality issues and their interaction with closed-loop supply chains, pp. 113-129, Springer, London.

Badenhorst, A., 2013a, 'A framework for prioritising practices to overcome costrelated problems in reverse logistics', Journal of Transport and Supply Chain Management 7(1), 1-10. http://dx.doi.org/10.4102/jtscm.v7i1.113

Badenhorst, A., 2013b, 'A best practice framework in reverse logistics', Thesis, Department of Transport, Logistics and Tourism, University of South Africa.

Bai, C. \& Sarkis, J., 2013, 'Flexibility in reverse logistics: A framework and evaluation approach', Journal of Cleaner Production 47, 306-318. http://dx.doi. org/10.1016/j.jclepro.2013.01.005

Bajor, I. \& Babić, D., 2014, 'Reverse logistics retail level return', International Journa for Traffic and Transport Engineering 4(2), 161-170. http://dx.doi.org/10.7708/ ijtte.2014.4(2).03

Bernon, M., Rossi, S. \& Cullen, J., 2011, 'Retail reverse logistics: A call and grounding framework for research', International Journal of Physical Distribution \& Logistics Management 41(5), 484-581. http://dx.doi.org/10.1108/09600031111138835

Bouzon, M., Govindan, K., Rodriguez, C.M.T. \& Campos, L.M.S., 2016, 'Identification and analysis of reverse logistics barriers using fuzzy Delphi method and AHP', Resources, Conservation and Recycling 108, 182-197. http://dx.doi.org/10.1016/j. resconrec.2015.05.021

Chan, F.T.S., Chan, H.K. \& Jain, V., 2012, 'A framework of reverse logistics for the automobile industry', International Journal of Production Research 50(5), 1318-1331. http://dx.doi.org/10.1080/00207543.2011.571929

Coyle, J.J., Langley, C.J., Jr., Novack, R.A. \& Gibson, B.J., 2013, Managing supply chains - A logistics approach, 9th edn., South-Western Cengage Learning, Mason.

Dutton, G., 2010, 'Reverse logistics: Money tree or money pit?', World Trade - WT100, viewed 03 September 2011, from http://www.worldtradewt100.com/articles/ reverse-logistics-money-tree-or-money-pit

Ganjali, M., Shirouyehzad, H. \& Shahin, A., 2014, 'Evaluating barriers of reverse logistics using DEMATEL method', Journal of Applied Science and Engineering Management 2(1), 51-61.

Genchev, S.E., Richey, R.G. \& Gabler, C.B., 2011, 'Evaluating reverse logistics programs: A suggested process formalization', International Journal of Logistics Management 22(2), 242. http://dx.doi.org/10.1108/09574091111156578

Greve, C. \& Davis, J., 2012, An executive's guide to reverse logistics: How to find hidden profits by managing returns, Kindle edn. Amazon, viewed 30 November 2016 from http://www.amazon.com/An-Executives-Guide-Reverse-Logistics/ dp/0983551405

Hammrich, D., 2007, 'Taking a look back helps retailers stay a step ahead Tapping into hidden revenues with returns management', Reverse Logistics Magazine, 5th edn., 2(2), 28-29, viewed 11 July 2012, from http://www. RLmagazine.com

Harris, C. \& Martin, K.B., 2014, 'The reverse logistics of online retailing, its evolution and future directions', Journal of System and Management Science 4(2), 1-14.

Hazen, B.T., Hall, D.J. \& Hanna, J.B., 2012, 'Reverse logistics disposition decisionmaking', International Journal of Physical Distribution \& Logistics Management 42(3), 244-274. http://dx.doi.org/10.1108/09600031211225954

Huang, Y. \& Yang, M., 2014, 'Reverse logistics innovation, institutional pressures and performance', Management Research Review 37(7), 615-641. http://dx.doi. org/10.1108/MRR-03-2013-0069

Janse, B., Schuur, P. \& De Brito, M.P., 2010, 'A reverse logistics diagnostic tool: The case of the consumer electronics industry', The International Journal of Advanced Manufacturing Technology 47(5-8), 495-513. http://dx.doi.org/10.1007/s00170Manufacturing

Jindal, A. \& Sangwan, S., 2015, 'Evaluation of collection methods in reverse logistics by using fuzzy mathematics', Benchmarking: An International Journal 22(3), 393-410. http://dx.doi.org/10.1108/BIJ-05-2013-0062

Kannan, G., Pokharel, S. \& Kumar, P.S., 2009, 'A hybrid approach using ISM and fuzzy TOPSIS for the selection of reverse logistics provider', Resources, Conservation and Recycling 54(1), 28-36. http://dx.doi.org/10.1016/j.resconrec.2009.06.004

Kaynak, R., Koçoğlu, I. \& Akgün, A.E., 2014, 'The role of reverse logistics in the concept of logistics centers', Procedia - Social and Behavioural Science 109, 438-442. http://dx.doi.org/10.1016/j.sbspro.2013.12.487

Khor, K.S. \& Udin, Z.M., 2012, 'Impact of reverse logistics product disposition towards business performance in Malaysian E\&E companies', Journal of Supply Chain Customer Relationship Management 2012, 1-19. http://dx.doi.org/10.5171/ 2012.699469

Kussing, U. \& Pienaar, W.J., 2012, 'Product returns and reverse logistics management', in W.J. Pienaar \& J.J. Vogt (eds.), Business logistics management, pp. 421-437, Oxford University Press, Cape Town.

Lambert, S., Riopel, D. \& Abdul-Kader, W., 2011, 'A reverse logistics decisions conceptual framework', Computers and Industrial Engineering 61(3), 561-581. $\mathrm{http}: / / \mathrm{dx}$.doi.org/10.1016/j.cie.2011.04.012
Laribi, L. \& Dhouib, D., 2015, 'Barriers to implementing reverse logistics in Tunisian companies', International Conference on Service Operations and Logistics, and
Informatics (SOLI 2015) Proceedings, November 15-17, 2015, Tunisia, pp. 145-153.

Lee, C.K.M. \& Lam, J.S.L., 2012, 'Managing reverse logistics to enhance sustainability of industrial marketing', Industrial Marketing Management 41(4), 589-598. http://dx.doi.org/10.1016/j.indmarman.2012.04.006

Lhafiane, F., Elbyed, A. \& Bouchoum, M., 2015, 'Reverse logistics information management using ontological approach', International Journal of Computer, Electrical, Automation, Control and Information Engineering 9(2), 396-401.

Li, Q., Luo, H., Xie, P., Feng, X. \& Du, R., 2015, 'Product whole life-cycle and omnichannels data convergence oriented enterprise networks integration in a sensing environment', Computers in Industry 70, 23-45. http://dx.doi.org/10.1016/j. compind.2015.01.011

Li, S., Wang, N., He, Z., Che, A. \& Ma, Y., 2012, 'Design of a multiobjective reverse logistics network considering the cost and service level', Mathematical Problems in Engineering 2012, 1-21. http://dx.doi.org/10.1155/2012/821215

Mai, E., Chen, H. \& Anselmi, K., 2012, 'The role of returns management orientation, internal collaboration, and information support in reverse logistics', Journal of Transportation Management 23(1), 45-59.

Mishra, R. \& Napier, R., 2014, 'Reverse logistics: Antecedents of successful implementation and firm performance effects', Journal of Supply Chain and Operations Management 12(2), 33-49.

Morgan, T.R., Glenn, R. \& Chad, R., 2016, 'Developing a reverse logistics competency: The influence of collaboration and information technology', International Journal of Physical Distribution \& Logistics Management 46(3), 293-315. http://dx.doi. of Physical Distribution \& Logistics
org/10.1108/IJPDLM-05-2014-0124

Myerson, P.A., 2015, Supply chain and logistics management made easy: Methods and applications for planning, operations, integration, control and improvement, and network design, Pearson Education, Old Tappan, NJ.

Olorunniwo, F.O. \& Li, X., 2010, 'Information sharing and collaboration practices in reverse logistics', Supply Chain Management: An International Journal 6, 454-462.

Partida, B., 2011, 'Leaders show power of reverse logistics', Supply Chain Management Review, November 2011, pp. 62-64, viewed 10 January 2015, from http://www.scmr. com

Patrican, J. \& Kirk, K., 2009, 'Competing and reversing revenue loss with aftermarket services', Reverse Logistics Magazine, 18th edn., 4(4), 12-15, viewed 18 September 2011, from http://www.RLmagazine.com

Prakash, C. \& Barua, M.K., 2015, 'Integration of AHP-TOPSIS method for prioritizing the solutions of reverse logistics adoption to overcome its barriers under fuzzy environment', Journal of Manufacturing Systems 37(3), 599-615. http://dx.doi. org/10.1016/j.jmsy.2015.03.001

Prakash, C. \& Barua, M.K., 2016, 'An analysis of integrated robust hybrid model for third-party reverse logistics partner selection under fuzzy environment',
Resources, Conservation and Recycling 108, 63-81. http://dx.doi.org/10.1016/j. Resources, Conservation
resconrec.2015.12.011

Rajagopal, P., Sundarm, V.P.K. \& Naidu, B.M., 2015, 'Future directions of reverse logistics in gaining competitive advantages: A review of literature', International Journal of Supply Chain Management 4(1), 39-48.

Robinson, A., 2015, 6 benefits of effective a reverse logistics system \& 9 core Revlog metrics to track, Cerasis, viewed 31 November 2015, from http://cerasis. com/2015/07/20/reverse-logistics-system/

Rogers, D.S., Lembke, R. \& Benardino, J., 2013, 'Reverse logistics: A new core competency', Supply Chain Management Review May/June, 40-47, viewed 10 January 2015, from http://www.scmr.com

Rogers, D.S., Melamed, B. \& Lembke, R.S., 2012, 'Modeling and analysis of reverse logistics', Journal of Business Logistics 33(2), 107-117. http://dx.doi.org/10.1111/ j.0000-0000.2012.01043.x

Rogers, L.K., 2010, 'Reverse logistics: Learn from your returns', Modern Materials Handling, September, 36-39, viewed 23 May 2011, from http://www.mmh.com/ article/reverse_logistics_learn_from_your_returns/

Rohan, P., Varun, S. \& Hulgur, C.S., 2012, 'Reverse Logistics', International Conference on Challenges and Opportunities in Mechanical Engineering, Industrial Engineering and Management Studies (ICCOMIM 2012) Proceedings, Bonfring, July 11-13 2012, pp. 885-892.

Rubio, S. \& Jimenez-Parra, B., 2014, 'Reverse logistics: Overview and challenges for supply chain management', International Journal of Engineering Business Management 6(12), 1-7. http://dx.doi.org/10.5772/58826

Rupnow, P., 2011, 'Time for some reverse logistics software', Reverse Logistics Magazine, 34th edn., 6(8), pp. 35-36, viewed 28 October 2012, from http://www. Magazine, 34th edn
RLmagazine.com

Saikiah, K., McRoberts, L. \& Thakur, R., 2016, 'The dynamics of returns management', viewed 12 January 2016, from http://www.sunlandlogisticssolutions.com/ wp-content/uploads/2016/01/WhitePaper_ReturnsManagement_ASU.pdf

Saunders, M., Lewis, P. \& Thornhill, A., 2012, Research methods for business students, 6th edn., Pearson Education, Harlow.

Shaik, M.N. \& Abdul-Kader, W., 2014, 'Comprehensive performance measurement and causal-effect decision making model for reverse logistics enterprise', Computers \& Industrial Engineering 68, 87-103. http://dx.doi.org/10.1016/ j.cie.2013.12.008

Sharma, S.K., Panda, B.N., Mahapatra, S.S. \& Sahu, S., 2011, 'Analysis of barriers for reverse logistics: An Indian perspective', International Journal of Modeling and Optimization 1(2), 101-106. http://dx.doi.org/10.7763/IJMO.2011.V1.18

Shukla, P., 2015, 'An analytical study of reverse logistics in business', Global Journal of Multidisciplinary Studies 5(1), 84-89. 
Srivastava, S.K., 2013, 'Issues and challenges in reverse logistics', in S.M. Gupta (ed.) Reverse supply chains - Issues and analysis, pp. 61-68, CRC-Press, Boca Raton, FL.

Starostka-Patryk, M., Zawada, M., Pabian, A. \& Abed, M., 2013, 'Barriers to reverse logistics implementation in enterprises', International Conference on Advanced Logistics and Transport (ICALT 2013) proceedings, Sousse, May 29-31, pp. 506-511.

Stock, J.R. \& Mulki, J.P., 2009, 'Product returns processing: An examination of practices of manufacturers, wholesalers/distributors, and retailers', Journal of Business Logistics 30(1), 33-62. http://dx.doi.org/10.1002/j.2158-1592.2009.tb00098.x
Tiwari, R.K., 2013, 'Identification of factors affecting reverse chain performance in relation to customer satisfaction using ISM modelling \& MICMAC analysis', Uncertain Supply Chain Management 1, 237-252. http://dx.doi.org/10.5267/j. uscm.2013.08.005

Wang, S. \& Zhang, S., 2009, 'Benchmarking model for reverse logistics entry by thirdparty providers', International Conference on Automation and Logistics (ICAL 2009) Proceedings, Shenyang, China, August 2009, pp. 2060-2065.

Wang, W., Liu, Y. \& Wei, Y., 2013, 'Research on management strategies of reverse logistics in e-commerce environments', Journal of System and Management Science 3(2), 45-50. http://dx.doi.org/10.1007/978-3-642-32054-5_48 